\title{
Innovative Photovoltaic Translucent Components for the Building Envelope
}

\author{
Rossella Corrao, Marco Morini, Luisa Pastore \\ Dipartimento di Architettura \\ Università degli Studi di Palermo, UNIPA \\ Palermo, Italy
}

\begin{abstract}
International directives that regulates buildings energy efficiency and environmental sustainability establish strict parameters for the construction of a new generation of "Zero Energy Buildings" indicating transmittance limits for building envelope components and encouraging the use of renewable sources. In this sense, the PV sector aims at the definition of novel efficient solutions for the integration in the building envelope, standing out for their multifunctional features. After an overview on the main PV technologies and building integrated applications, focusing on semi-transparent envelope solutions, the paper shows the results of a research that is being carried out at the Department of Architecture of the University of Palermo, aimed to define innovative solutions for the construction of photovoltaic and energy efficient translucent building envelopes. In particular, the research focuses on the optimization of glassblock panels in terms of thermal insulation, light transmittance, energy production and mechanical resistance. New configurations of glassblock were designed in order to reduce its $U$ value and integrate $3^{\text {rd }}$ generation $P V$ technologies for the production of green energy. Furthermore, a dry assembly system has been designed for the construction of translucent prestressed panels made of DSC integrated glassblocks that are able to guarantee high levels of resistance to horizontal actions and to build translucent, photovoltaic and efficient building envelopes even in dry, tropical and temperate areas or in unfavourable light conditions.
\end{abstract}

Index Terms—Building Envelope, DSC, Glassblock, BIPV

\section{INTRODUCTION}

As shown by contemporary architectural trends, nowadays glass turns out to be diffusely used for the construction of transparent or translucent envelopes for both new and retrofitted buildings. Nevertheless, glazed surfaces represent an awkward aspect among the buildings envelope components, since their thermal resistance is generally lower than the opaque ones. This is essentially due to the energy transmission occurring through glazed surfaces, possibly causing - if not accurately controlled - excessive heat loss during winter and indoor overheating during summer. Moreover, the European Directive on Energy Performance of Buildings, recast in 2010, restates the necessity to improve the overall energy efficiency of new buildings and existing buildings during their significant renovation, calling international attention to the urgency of drawing up national plans for the construction of nearly zeroenergy buildings and taking into account, at the same time, the building typologies and national, regional or local climatic conditions.

Geographical areas such as the Mediterranean Basin, indeed, may represent "adverse" climate contexts for the construction of transparent or translucent building envelopes, due to the high temperatures and solar radiation levels during the whole year. But if, on the one hand, solar radiation in warm and hot zones could origin thermal and visual discomfort inside the buildings, the advantages derived from the exploitation of sunlight for the production of energy are, on the other hand, fully acknowledged. For this reason, international directives provide national or regional energy performance requirements for fully integrated overall energy performance also boosting the use of novel and efficient technological solutions for buildings energy autonomy.

The architectural integration of renewable energy sources plays an important role allowing the building to transform itself from a simple consumer to an effective producer of clean energy. In particular, research and market interests have been recently focusing on photovoltaic technologies considering their energy performance and their predisposition for the architectural integration. Growing attention for the Building Integrated Photovoltaic (BIPV) sector is also demonstrated by the increase of international research projects, mostly cofunded by the EU, that have been established in the last years with the aim of providing a harmonized normative basis for the application of BIPV in Europe since PV modules and systems are still lacking of specific standards for their regulation [1].

\section{BIPV - BULDING INTEGRATED PHOTOVOLTAICS}

With BIPV is meant a multifunctional technology where the PV module coincide with a technical element of the building envelope, thus able not only to produce energy but also to provide other functions that are typical of the building envelope itself (such as thermal and acoustic insulation, air tightness, water tightness, modulation of the light coming from the outdoor environment, aesthetic characterisation and so on).

The multifunctionality of the BIPV products eliminates the need of some traditional non-PV building elements (closure components, shading devices etc.) and reduces the building costs particularly related to the additional supporting structures of the PV panels. 
A great variety of BIPV products, arisen from the collaboration of PV and building industries, has been launched in the market during the past decade, thanks to the technological progresses that allowed the definition of solar modules with new features, particularly fit for building integration, such as lightness, flexibility, variety of colours and finishing.

\section{A. From $1^{\text {st }}$ to $3^{\text {rd }}$ generation PV technologies}

$1^{\text {st }}$ generation PV technology, based on the use of crystalline silicon, still dominates the market since it is one of the most diffused and consolidated knowledge. Despite the higher values of nominal efficiency silicon panels needs an oriented installation to offer the best performance.

Big efforts have been made for the development of $2^{\text {nd }}$ generation thin film solar cells that - thanks to characteristics such as lightness, superficial homogeneity and thinness - have further widened the range of building-integrated applications with some valuable results in terms of aesthetic quality.

Eventually, it is in $3^{\text {rd }}$ generation technologies (DyeSensitised Solar Cells - DSC, Organic Photovoltaics - OPV) that a big part of the Scientific Community acknowledges the biggest potential in the field of BIPV. These technologies that are still in a preindustrial phase provide a real answer to the new tendencies that PV industry is currently heading to: semitransparency, flexibility, lightness, versatility, sustainability. $3^{\text {rd }}$ generation technologies are based on the use of organic semiconductors; they are economic, lightweight and easily printable on rigid or flexible substrates, furthermore offering a complete versatility for building integration. Differently than silicon wafer, these devices maintain good values of efficiency even in low light conditions (diffuse or artificial illumination) thus not needing an oriented positioning, with obvious advantages in terms of architectural integration on the building façades and/or roofing, hardly ever coinciding with the optimal directions for maximum solar irradiation.

\section{B. Semi-transparent PV solutions}

The envelope plays a central role in the design of energy efficient buildings, since it is the technical element fundamentally dedicated to the control and regulation of the energy fluxes between external and internal environments. A lot of PV building integrated solutions entered the market in order to substitute transparent or translucent surfaces of the building envelopes. Generally, sandwich structures are used, including transparent substrates that can be provided of particular characteristics - thermo-acoustic insulation, mechanical resistance, optical properties - and aesthetical features derived from particular treatments of the PV modules. Speaking more in detail of the transparency, since silicon wafers are opaque, in $1^{\text {st }}$ generation BIPV products semitransparency is achieved through distancing the single cells or riddling them with holes.

The two methods, which imply a sensible increase in the costs of production of the PV panels, allow to reach degrees of Transparency up to about $20 \%$ but, of course, this corresponds

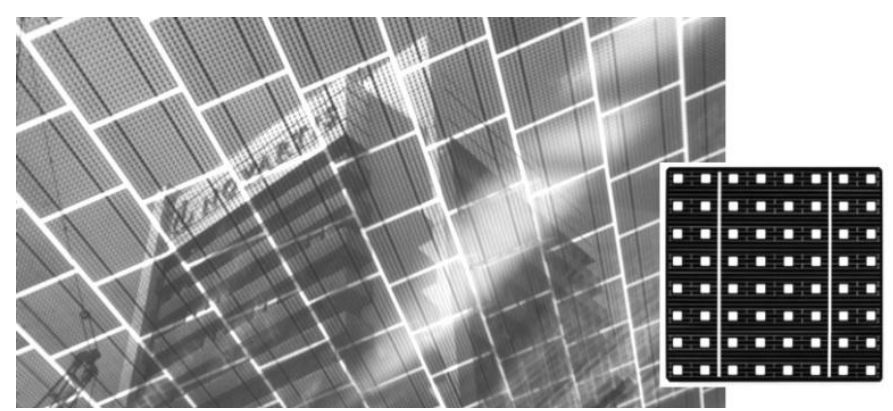

Figure 1. Novartis Gehry Building, Basel, Frank O. Gehry. View of the PV roof in semi-transparent silicon panels and detail of a cell

to a growing decrease in active area and thus in the power of the modules.

Semi-transparent PV modules enable to obtain a shadowing effect (which can also be "designed") that, especially on southern façades, may be fundamental for the achievement of acceptable conditions of indoor comfort, however continuing to produce clean energy. In this case the PV panel substitute not only the transparent surfaces but also technical components of the building envelope such as sun shading devices, producing economies in the construction phase. Low percentages of semitransparency in $2^{\text {nd }}$ generation technologies are due to the micrometric thickness of the PV film but higher values (up to about $20 \%$ ) can be obtained through a mechanical process of perforation of the PV film with the same implications -in terms of electric power and additional costs of the panels- already discussed for $1^{\text {st }}$ generation technologies. $3^{\text {rd }}$ generation technologies, instead, are semi-transparent devices. In DSCs, for example, higher or lower degrees of light transmission can be easily obtained through an adequate design of structure, thickness and molecular dimension of the active layers (semiconductor film and dye cocktail). So, differently from $1^{\text {st }}$ and $2^{\text {nd }}$ generation technologies, higher degrees of semitransparency in DSCs -but also in OPVs- are achievable without a reduction in the active area of the solar modules. However, this corresponds to a decrease in the efficiency of the devices, which depends on the lower amount of light absorbed for the energy conversion by high-transparency DSC devices. In particular, DSC semi-transparency, together with coloration and design, may be easily tuned in virtually unlimited combinations without any additional productive machinery or any modification in the productive process, which is based on printing systems for the deposition of the active layers of the solar devices ${ }^{\mathrm{a}}$.

Features derived from BIPV regard the aspects related not only to the energy production but also to the functionality and the aesthetics of the building envelope, as well as the energy saving of the whole building to which the BIPV components may contribute. For these reasons a systemic approach turns

\footnotetext{
${ }^{\text {a }}$ DSCs are particularly fit for a mass customized production in line with what is requested today to the PV and building sectors.
} 
out to be necessary for the building design in order to study the features of the PV installation as a part of the design process.

A remarkable outline of this sustainable and systemic approach is demonstrated by the design of the Sports Hall in Burgweinting, Regensburg ${ }^{b}$ (Fig. 2) in which a multidisciplinary team of engineers, architects and researchers from the Fraunhofer Institute for Solar Energy has been involved to resolve, in particular, the issues related to the glazed crowning running through all the perimeter of the building. The main issue regarded the south façade that, if not accurately designed in terms of light transmission, thermal insulation, shadowing properties, would have compromised the comfort conditions inside the hall. After a number of software simulations and studies of the context, the team came up with an energy efficient solution, involving BIPV glazed components. A PV installation was integrated on the south façade of the glazed crowning of the building. In particular, 98 panels in polycrystalline silicon integrated on safety glass were used to contribute to the efficiency of the building, not only through the PV production but also with their features as technical elements of the building envelope. The $20-\mathrm{mm}$ distance between silicon cells has been calculated in order to guarantee the optimal level of natural illumination and avoid dazzling effects. The inner glass sheet of the sandwich is reinforced to provide the adequate mechanical resistance, as it should be required in a sports hall; the outer glass sheet is coated of a low-emission oxide, in order to reduce heat losses during winter and summer overheating. The glazed elements on the other façades have also been accurately studied and each has been provided of a different glazed solution, from the low-e coated glass panels on the north side to the light-scattering properties of those on the east and west sides [2].

Also in the retrofit of the Schott Iberica Building, in Barcelona (Fig. 3), the southwest façade were retrofitted through a BIPV installation. The PV panels, composed of a coloured glass substrate and of amorphous silicon semitransparent PV modules (with a $10 \%$ transparency obtained through the perforation of the PV film) were installed as windows, substituting the previous fixed windows of

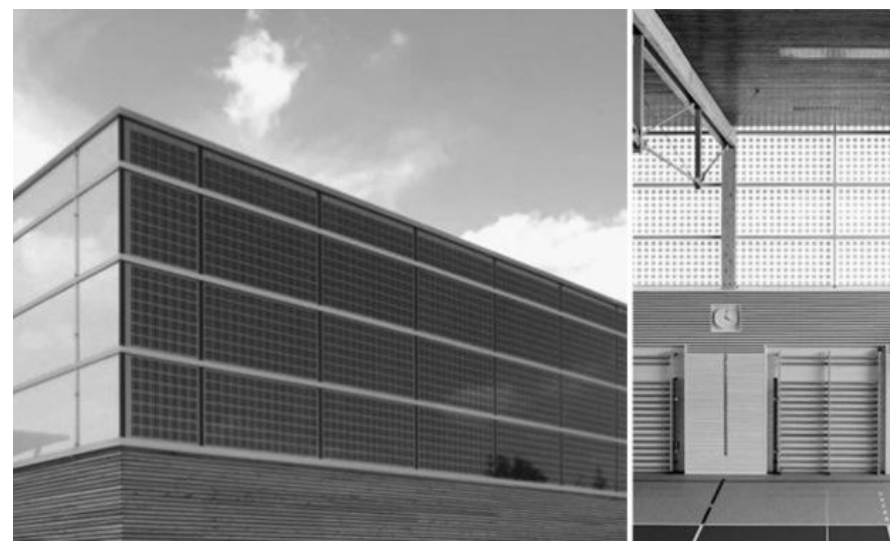

Figure 2. Sports Hall in Burgweinting, Regensburg. internal and external view of the PV translucent façade

b 2004, Regensburg Building Department, Tobias Ruf and Fraunhofer ISE.

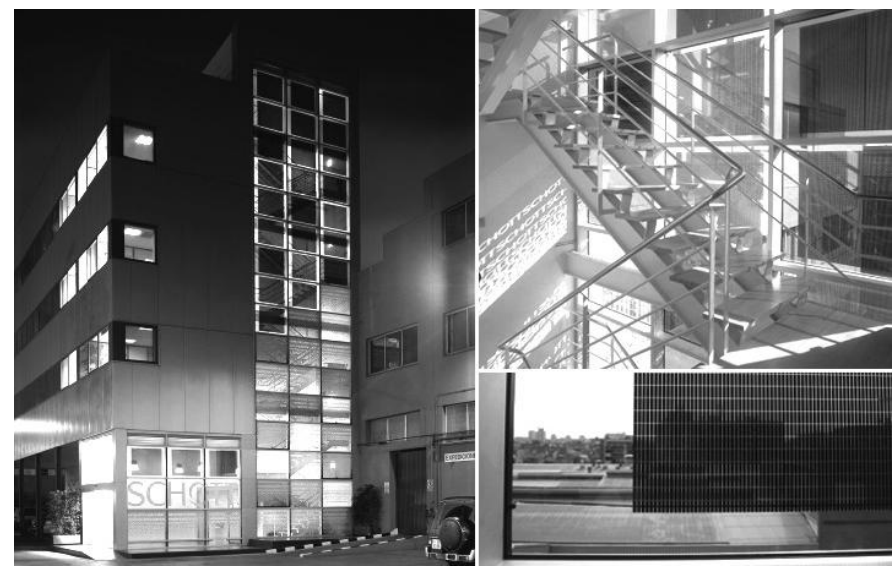

Figure 3. SCHOTT Iberica Building, Barcelona. General and detailed views of the multi-coloured BIPV glazing on the south-west façade

translucent glass which generated, during summer, unsustainable internal temperatures (up to $50^{\circ} \mathrm{C}$ ). Thanks to this multi-coloured ${ }^{c}$ installation only, also provided of an opening system for natural ventilation, the annual energy consumption of the building decreased of about the $8 \%$.

\section{DSC-INTEGRATED GLASSBLOCKS PANELS FOR ACTIVE FAÇADES AND ROOFS}

An innovative multifunctional dry-assembled glassblock panel, which integrates $3^{\text {rd }}$ generation dye-sensitised solar cells, has been developed at the Department of Architecture of the University of Palermo, with the aim to construct translucent building envelopes able to produce green energy and reduce the energy consumptions while guaranteeing the structural safety of the building envelope.

Compared to single pane windows, glassblock provides, for its configuration, higher energy performance, which makes it particularly suitable for the construction of sustainable building envelopes. In addiction to this, glassblock integration with DSCs (Corrao, Morini, 2012) enables the construction of efficient and photovoltaic roofing and/or façades of building that may be located in warm and hot areas like the Mediterranean Basin. This is also due to the fact that, contrary to $1^{\text {st }}$ and $2^{\text {nd }}$ generation PV technologies, DSCs do not suffer from high operating temperatures.

Besides producing clean energy, the multifunctional PV glassblock panels are able to reduce the building consumptions, consequently bringing down the $\mathrm{CO}_{2}$ emissions in the atmosphere. The new configurations of glassblock contribute to the improvement of the energy efficiency of the envelope, possibly reducing the need for expensive and polluting air conditioning systems; on the other hand, thanks to the versatility of DSCs, it is possible to tune the transparency of the cells ${ }^{\mathrm{d}}$ in order to modulate the sunlight coming inside the

${ }^{\mathrm{c}}$ The different colours of the panels (SCHOTT ${ }^{\circledR}$ ASIThru) were given by the glass substrates $\left(\mathrm{SCHOTT}^{\circledR}\right.$ Imera) and did not depend on particular treatment of PV amorphous silicon film, as instead happens in $3^{\text {rd }}$ generation devices.

d Simply intervening on the cells nanometric architecture, choosing their colour -thus selecting the wavelengths allowed in the building- or designing adequate patterns on the glassblock surface. 
building, according to the outdoor climate conditions, the comfort levels required by users and the requested efficiency of the PV systems. In this regard, analytical simulations ${ }^{\mathrm{e}}$ have been carried out to evaluate the optical transmittance, solar factor and shading coefficient in relation to four different hypotheses of DSC integration with the glassblock ${ }^{\mathrm{f}}$. The values of transmittance, reflection, absorption and refractive indices of the cells materials have been used as inputs data, while taking into consideration the range of wavelengths from 400 to 1400 $\mathrm{nm}$ and a power of the sunlight beam of $845 \mathrm{~W} / \mathrm{m}^{2}$ referring to the solar spectrum AM 1.5.

Through these simulations the configuration that considered the application of the DSC on the external face of the glassblock has been identified as the most efficient and further analyses have been carried out on $1.80 \mathrm{~m}^{2}$ panels which show that, depending on the different configuration of DSC integration with the glassblock, the power can vary from 59 to $122.5 \mathrm{Wp}$ according to a range of module area per glassblock moving from $65.70 \%$ to $93.78 \%$.

Table 1. Calculated power of $1.80 \mathrm{~m}^{2}$ panel made of DSC-integrated glassblocks according to the four different configurations

\begin{tabular}{ccc} 
Hypotheses & Power $(\mathbf{W p})$ & Module area $(\boldsymbol{\%})$ \\
\hline 1 & 104.50 & 80.06 \\
2 & 122.50 & 93.78 \\
3 & 93.00 & 73.60 \\
4 & 59.00 & 65.70
\end{tabular}

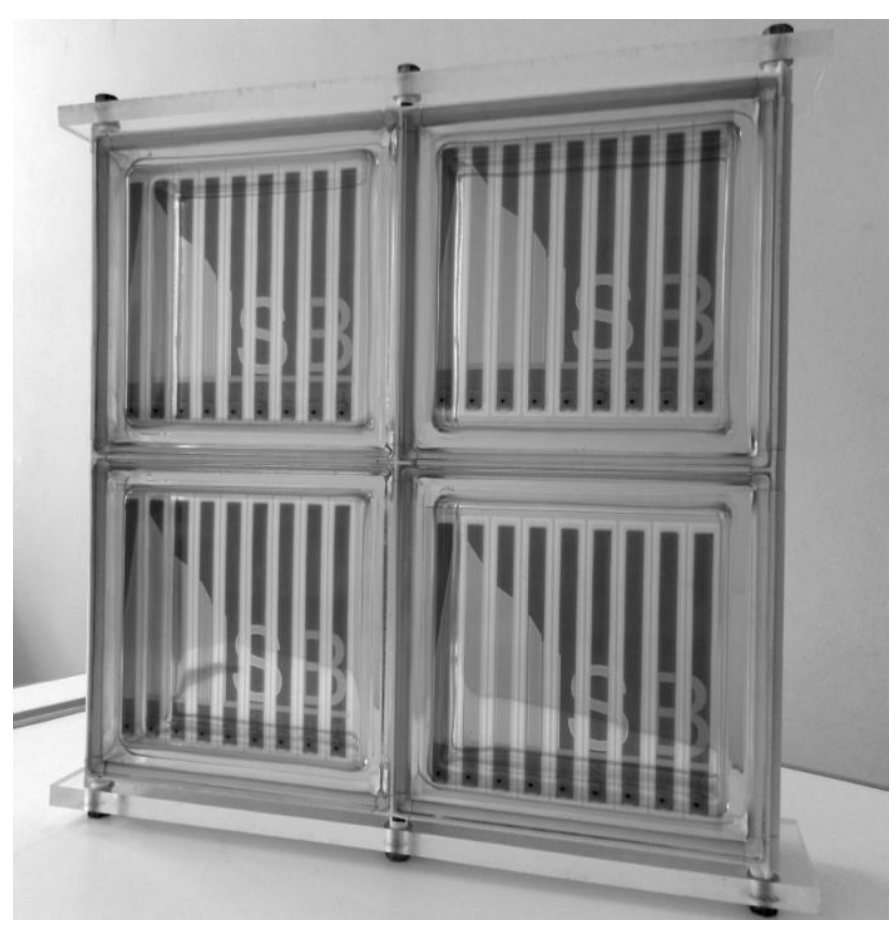

Figure 4. Prototype of dry-assembled DSC-integrated glassblocks

${ }^{\mathrm{e}}$ Simulations were performed with the software Zemax.

${ }^{\mathrm{f}}$ The Hypotheses foresee the integration of the DSC device in different positions: on the external face of one of the two glass shells composing the glassblock (Hyp. 1 and 2); on the internal face of said glass shell (Hyp. 3); in the centre of glassblock cavity - where the DSC module is inserted by means of a plastic 'thermal belt' - dividing it into two sub-cavities (Hyp. 4).
Using this kind of panels it is possible to easily build active translucent building envelopes even in high-rise building. Glassblock is a building product diffusely used in the world for the construction of translucent building envelopes [5] and has been mainly "wet-assembled" until now. Glassblock panels have traditionally been installed as building components filling the spaces between the structural elements. Steel bars, positioned in the cavities between the glassblocks, are used to stiffen the panels and then mortar is put in the same cavities where the steel bars are placed in order to joint all the elements together. This type of "wet assembly" system enables the construction of glass walls (made of panels or not) with joints that are more than $1 \mathrm{~cm}$ thick; moreover, this system does not allow translucent panels to immediately achieve adequate levels of mechanical resistance because of the mortar setting time. For the construction of translucent envelopes even in high-rise buildings, it is necessary to overcome the limits due to the traditional assembly system that has been used so far to build panels for external use. Actually, in high-rise buildings the problems related to the action of horizontal forces, such as wind and earthquake, must be taken into account, as well as the necessity to speed up the construction of the building envelope, in order to reduce the building costs. For these reasons, a "dry assembly system" has been developed. It enables to build precast and monodirectionally prestressed translucent panels able to better respond to horizontal actions, especially when the panels are used in high-rise buildings. The dry assembled glassblock panel is characterized by a supporting structure constituted by plastic vertical and horizontal profiles provided with holes for the passage of stiffening steel bars that are positioned along the prevalent dimension of the panel, running lengthwise through the vertical profiles and crosswise through the horizontal ones. The steel bars are stressed through clamping nuts in order to apply the unidirectional compressing force to the panel that is able to guarantee high levels of mechanical resistance against horizontal actions due to, e.g., wind and earthquakes. The profiles are also provided with special lodgings for the electric interconnections between the PV modules - which coincide with the DSC integrated glassblocks - and of little projecting wings that generate only $2 \mathrm{~mm}$-thick joints, significantly smaller than those deriving from the use of the wet assembly system. These panels can be easily connected to the load-bearing structure of buildings through mechanical assembly systems that enables to reduce time for the construction of high-rise buildings.

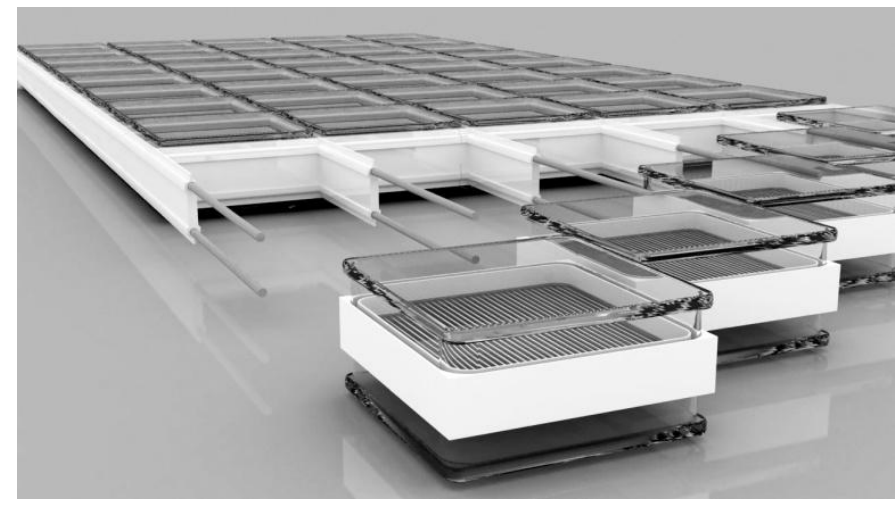

Figure 5. Assembly of the multifunctional translucent PV panel made of DSCintegrated glassblocks 
Analitical simulations and laboratory tests have been carried out during the research to test the mechanical resistance of such dry-assembled panels, initially taking into account traditional glassblocks. In particular, mechanical performance was first assessed through the use of Strauss Software, which enabled to run simulative analyses on 3D models of the panels. The maximum resistance evaluated for a $2 \mathrm{~m}^{2}$ dry-assembled glassblock panel, made of 50 pieces with $2 \mathrm{~mm}$ joints, was of $447 \mathrm{kgf} / \mathrm{m}^{2}$. Laboratory tests on a real prototype confirmed the results of the simulation analyses previously performed. The bending resistance tests were performed loading the panel by using inflatable mattresses progressively filled with water up to a 650-kgf and then progressively unloading it. The panel was prestressed by applying a twisting couple through nuts of $0.7 \mathrm{kgf}$ corresponding to an axial pressing force of $446 \mathrm{kgf}$ for each bar and showed an elastic behavior up to the maximum load it was exposed to. The panel performance was fully satisfying and the test was interrupted at $650 \mathrm{kgf}$ although the test could proceed further (since the panel was still in the elastic phase). In particular, the maximum load tested - being the area of the panel of $1.8 \mathrm{~m}^{2}$ - corresponds to about $360 \mathrm{Kgf} / \mathrm{m}^{2}$.

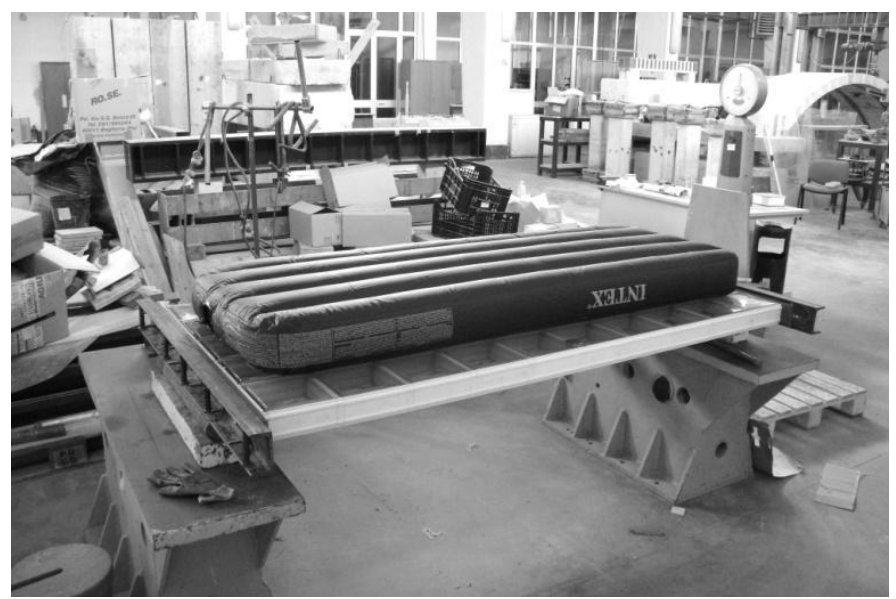

Figure 6. Laboratory load test on a $1.80 \mathrm{~m}^{2}$ dry-assembled panel

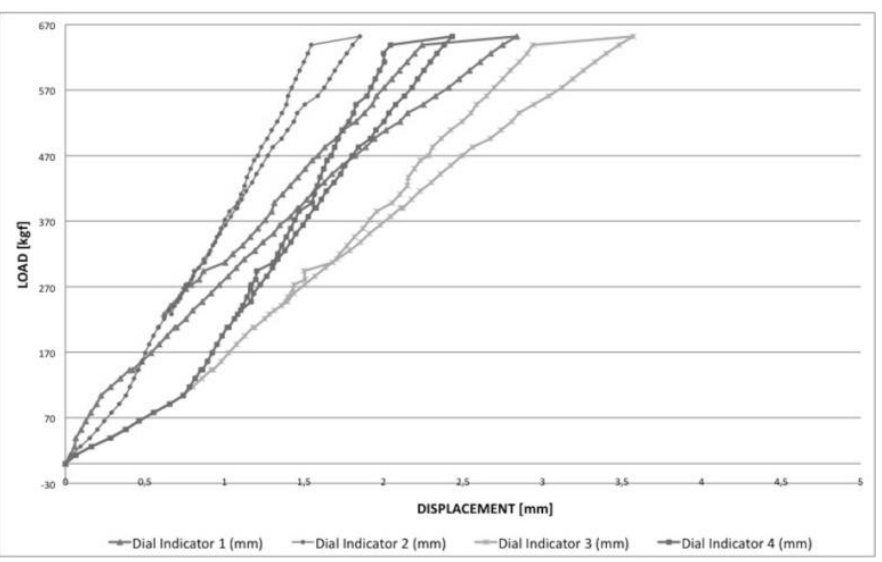

Figure 7. Load-Displacement graph referred to measurements registered by four dial indicators
Contemporary international architecture trends demonstrate that the use of glazed surfaces for the construction of transparent or translucent building envelopes turns out to be largely diffused for the design of both new and retrofitted buildings, even where climate conditions are "adverse" because of the high solar radiation levels. In this sense, the BIPV sector aims at the definition of novel efficient solutions for building integrated PV technologies, with focus on building envelope components.

The research that is being carried out at the Dept. of Architecture in Palermo, shown in this paper, is aimed to define innovative translucent $\mathrm{PV}$ panels that integrate $3^{\text {rd }}$ generation PV technology for BIPV. Using this kind of panels it is possible to easily build active translucent building envelopes even in warm and hot climate context and to characterize the appearance of the buildings, thanks to the possibility to easily vary shape and colour of the solar cells. Four different hypotheses of integration of the DSCs into the glassblock have been analysed and tested and in this regard the percentage of active area per square meter of panel, reach values that are higher than $80 \%$, equating the "traditional" silicon panels on glass substrate, compensating the loss of active surface due to the presence of joints and borders through the integration inside the panel of the load bearing structures and of the electrical connections and conferring, at the same time, the maximum material continuity to the glazed façade or roof.

Optical analyses demonstrated that, considering a $30^{\circ}$ South orientation, $15.30 \mathrm{~m}^{2}$ of DSC-integrated glassblock panels are needed to produce $1 \mathrm{kWp}$, while for traditional opaque crystalline silicon PV cells $6-8 \mathrm{~m}^{2}$ are required.

More analyses are being conducted to individuate the most energy efficient configuration of DSC-integrated glassblock and to implement the electrical connections of the panels.

\section{REFERENCES}

[1] F. Reil, J. Althaus, T. Szacsvay, C. Erban, H. Remmels, "Progress in European BIPV Standardization Work - Definition of Test Sequences and Test Requirements", in Proceedings of the $27^{\text {th }}$ European Photovoltaic Solar Energy Conference and Exhibition, 2012, pp. $4212-$ 14.

[2] C. Hemmerle, S. Jakubetz, S. Unnewher, B. Weller, Photovoltaics, Technology Architecture Installation, Birkhauser, 2010.

[3] D. Cappello, M. Beccali, R. Corrao, P. Mannino, "Nuove configurazioni del vetromattone. Simulazioni dinamiche per la valutazione delle prestazioni ottiche e termiche", in Rivista della Stazione Sperimentale del Vetro, vol.41, n. 5, 2011, pp. 5-14.

[4] R. Corrao, M. Morini, "Integration of Dye-Sensitized Solar Cells with Glassblock", in Czasopismo Techniczne. Budownictwo - Thecnical Transactions, Politechnika Krakowska, Issue 3, Year 109, 2012, pp. 5564.

[5] R. Corrao, Glassblock and Architecture. Evoluzione del Vetromattone e Recenti Applicazioni, Firenze, Alinea Editrice, 2010.

[6] R. Corrao, M. Morini, L. Pastore, "Active Traslucent Envelopes in Warm and Hot Areas. An innovative multifunctional, dry-assembled components for BIPV", in Proceedings of the $2^{\text {nd }}$ Annual Conference on Architecture and Civil Engineering (ACE 2014), 24-25 ${ }^{\text {th }}$ March 2014, Singapore, pp. 168-172. 
Rossella Corrao. Arch, $\mathrm{PhD}$ in Building Engineering: Design Techniques and Building Production, Associate Prof. at the Dept. of Architecture of the Polytechnic School of Palermo. In recent years her research activity has been aimed to the analysis of problems related to the use of high technology materials for the performance enhancement of light-capturing elements of the building envelope. She is author of several books and scientific publications and co-author of 2 patents and 1 PCT.

Since 2013 she is co-founder of SBskin.

Smart Building Skin, a technological startup and spin-off of the University of Palermo, which deals with innovative and energy-efficient building components.

Marco Morini. Marco Morini (1988) is an Architectural Eng. and PhD Student in Architecture with a thesis about Building Integrated Photovoltaics. He graduated in 2012 with a degree thesis titled: "Integration of third generation solar cells with the glassblock for the construction of translucent photovoltaic building envelopes". He developed research experience between
Europe and USA. Since 2012, he produced several scientific publications on conference proceedings, books and journals.

He's co-author of 1 patent and 1 PCT.

Since 2013 he is co-founder of SBskin. Smart Building Skin, a technological startup and spin-off of the University of Palermo, which deals with innovative and energy-efficient building components.

Luisa Pastore. Luisa Pastore (1985) is an Architectural Engineer and a $\mathrm{PhD}$ in Recovery of Existing Buildings and Innovative Processes in Architecture. During the last five years she gained a wide research and work experience abroad where she specialized in sustainable architecture, with focus on the energy retrofit of the existing building stock. She is author of works published in books, conference proceedings and journals and co-author of 2 patents and 1 PCT

Since 2013 she is co-founder of SBskin. Smart Building Skin, a technological startup and spin-off of the University of Palermo, which deals with innovative and energy-efficient building components. 